\title{
Proximity and size of neighbouring habitat affects invertebrate diversity
}

\author{
Bayden D. Russell*, Bronwyn M. Gillanders, Sean D. Connell \\ Southern Seas Ecology Laboratories, Darling Building DP418, School of Earth and Environmental Sciences, \\ University of Adelaide, South Australia 5005, Australia
}

\begin{abstract}
Species richness and abundance of animals in a particular habitat are often not independent of neighbouring habitats. Concern centres on whether changes to adjacent habitats (e.g. unprotected habitats) can affect the conservation value of protected habitats. The extent to which these concerns are real may be affected by differences in dispersal mode and capacity of the target animals. We tested the interactive effects of size (small vs. large) and isolation (near vs. far) of neighbouring habitats on the assemblage composition, species richness and abundance of 2 taxonomic groups with contrasting adult dispersal modes; copepods as water column swimmers and polychaetes as benthic crawlers. Artificial habitats that are structurally similar to natural articulated coralline algae were used because manipulation of habitat size (small: $40 \times 40 \mathrm{~mm}$, large: $120 \times 120 \mathrm{~mm}$ ) and isolation (near $100 \mathrm{~mm}$, far $300 \mathrm{~mm}$ ) was easier. The different levels of size and isolation used were within the range seen in natural habitats at the study site. Isolation of habitats had a greater effect on assemblages of polychaetes, as may be expected for more limited dispersers. The composition of polychaetes differed between near and far habitats independent of their size, while copepod composition only differed between sizes of habitat when they were far apart. While we predicted that greater abundance and species richness would occur in habitats adjacent to large habitats, only polychaetes were consistent with this pattern. Copepod richness and abundance, in contrast, were greater in habitats that were far from small habitats, providing evidence for the 'nearest refuge hypothesis'. These results reinforce the need to consider issues of dispersal and proximity to neighbouring habitats when planning protected areas to achieve conservation goals.
\end{abstract}

KEY WORDS: Habitat fragmentation - Habitat loss · Isolation · Protected areas · Dispersal Resale or republication not permitted without written consent of the publisher

\section{INTRODUCTION}

Natural systems are often composed of discrete habitat patches (Pickett \& White 1985). Contrary to early theory that patchiness creates isolated populations of species, it is now recognised that populations in neighbouring habitats are often linked (Wiens et al. 1993, Hanski 1999). The degree to which populations in neighbouring habitats interact depends on many factors, including individual habitat size (Anderson 1998, Fleishman et al. 2002), amount of habitat in a landscape (Delin \& Andrén 1999, Lee et al. 2002, Fahrig 2003), distance to other habitats (Golden \& Crist 1999, Lomolino \& Perault 2001, Fleishman et al. 2002) and shape and spatial arrangement of habitats (Collinge 1998, Flather \& Bevers 2002, Tanner 2003). The inter- actions between these factors are often difficult to separate, such that incorrect conclusions can be drawn about their independent effects (Trzcinski et al. 1999, Fahrig 2003).

The recognition that habitats are not independent of each other has led to concern that reserves in proximity to inappropriate habitats may compromise their ability to act as a biodiversity repository (Lenihan et al. 2001). The extent to which this concern is real, may depend on the size and distance to neighbouring habitats, and more importantly, the effect of modes of dispersal of target organisms (Virnstein \& Curran 1986, Edgar 1992, Eggleston et al. 1999, Trzcinski et al. 1999). Although size of habitat seems to have similar effects on many species (Fahrig 2003), distance between habitats seems to have less effect on animals 
with higher dispersal abilities, such as birds (Andrén 1994, Trzcinski et al. 1999, Lee et al. 2002), than animals with lower dispersal abilities, such as mammals (Andrén 1994, Delin \& Andrén 1999, Lomolino \& Perault 2001). Bowman et al. (2002) classified dispersal abilities of species into ground, near-ground or aerial categories. There are large differences between dispersal modes in marine systems, therefore size and isolation of habitats affect taxonomic groups in different ways (Edgar 1992, Eggleston et al. 1999, WaageNielsen et al. 2003). Highly mobile crustaceans, such as amphipods and copepods, tend to disperse between habitats by swimming through the water column and therefore colonise habitats quickly and over large distances (Gunnill 1982b, Virnstein \& Curran 1986, Howard et al. 1989, Edgar 1992, Eggleston et al. 1998). In contrast, polychaetes and gastropods that primarily disperse by crawling or walking along the substrate tend to colonise habitats at a slower rate and are more likely to be affected by increased isolation of habitats (Virnstein \& Curran 1986, Howard et al. 1989, Edgar 1992, Jørgensen \& Christie 2003).

It is well documented that a loss in habitat area is associated with loss in diversity and number of animals (Fahrig 2003). Most studies investigating the effects of habitat size (or habitat loss) are constrained to sampling habitats of different size and then standardizing data per unit area (e.g. Gunnill 1982a, Collinge 1998, Eggleston et al. 1999, Golden \& Crist 1999). Few studies maintain habitats at a constant size and manipulate the size of neighbouring habitats to separate the effect of size and isolation as components of fragmentation. In our study, the size of experimental habitats was fixed, in order to investigate the interactive effect of size (small vs. large) and isolation (near vs. far) of neighbouring habitats. By altering the size of neighbouring habitats and the distance between habitats, we were able to separate the effects of amount of habitat in a landscape (size within isolation) and isolation of habitats (isolation within size).

Manipulating habitat size and isolation on large scales presents logistical problems (e.g. grasslands or forests), so we manipulated artificial habitats in a small-scale experiment in a subtidal marine system. Small-scale experiments enable replication often not possible in landscape scale experiments (Delin \& Andrén 1999) and provide valuable information on responses of animals to habitat size and isolation (Bell \& Hicks 1991, Eggleston et al. 1999, Goodsell \& Connell 2002). The artificial habitats used were structurally similar to natural habitats (articulated coralline algae) and ranges in size and isolation were comparable to those of natural habitats at the field site. We compare the effects of size and isolation of neighbouring habitat on 2 taxa with different modes of adult dispersal, copepods (water column dispersal) and polychaetes (benthic dispersal). We predicted that isolation of habitats would have a greater effect on composition of polychaete assemblages than copepod assemblages because of this difference in mobility. Furthermore, we expected that habitats near to large habitats would have greater abundance and species richness of animals than habitats near to small habitats, and that habitats far from small habitats would have the least abundance and richness of animals.

\section{MATERIALS AND METHODS}

Experimental design. An experiment was carried out on open patches of subtidal sand ( $5 \mathrm{~m}$ depth) in Abalone Cove, West Island, South Australia $\left(35^{\circ} 36^{\prime} \mathrm{S}\right.$, $\left.138^{\circ} 35^{\prime} \mathrm{E}\right)$ to test the effects of size of neighbouring habitat (small vs large), isolation of habitat (near vs. far) and duration (2 or 13 d) on faunal diversity and abundance ( $\mathrm{n}=7$ experimental habitats/treatment/ time). Experimental habitats were set up as pairs of habitats (neighbouring habitats) on the sand flat. Only 1 habitat from each pair was sampled (sampled habitats) and all sampled habitats were the same size (small), removing the potential for size of the sampled habitats to influence the results. Only the neighbouring unsampled habitat varied in size (either small or large). The sand flat was used because sand represented a barren matrix that is flat and structurally simple, unlike the experimental habitats. Replicate pairs of habitats were separated by a minimum of $2 \mathrm{~m}$ to ensure independence (Holmquist 1998, Goodsell \& Connell 2002).

The experimental habitats used were commercially available artificial turf, which provided discrete but complex habitats $(40 \mathrm{~mm}$ long $\times 40 \mathrm{~mm}$ wide $\times 50 \mathrm{~mm}$ tall) that could be easily manipulated to form different sized habitat patches. Experimental habitats were attached to granite boulders (approximately 150 to $200 \mathrm{~mm}$ in diameter) that were devoid of marine life and wrapped in plastic mesh to aid attachment to experimental habitats. These habitats were analogous to the physical complexity of naturally occurring articulated coralline algae (Melville \& Connell 2001), which act as habitat for mobile invertebrates (Wellenreuther \& Connell 2002). Small patches of habitat measured $40 \times 40 \mathrm{~mm}$ and large patches were $120 \times 120 \mathrm{~mm}$. The 2 levels of isolation between neighbouring habitats were $100 \mathrm{~mm}$ (near) and $300 \mathrm{~mm}$ (far) at the nearest edge of the habitats (Fig. 1). These habitat sizes and distances between habitats were within the range of natural articulated coralline algae at the study site (B. Russell unpubl. data), and have been used for colonisation experiments of articulated coralline turfs 




Fig. 1. Diagram illustrating the arrangement of the experimental habitats in their pairs

(Kelaher \& Rouse 2003). Previous studies have shown that artificial habitats are readily colonised by diverse species of macro-invertebrates, including crustaceans and polychaetes (Myers \& Southgate 1980, Costello \& Myers 1996, Hall et al. 2000, Norderhaug et al. 2002, Smith \& Rule 2002).

Timing and sampling. The 2 taxonomic groups used in this study, copepods and polychaetes, immigrate into habitats at different rates (Gunnill 1982b, Bell \& Hicks 1991, Jørgensen \& Christie 2003), possibly because of different adult dispersal modes. The polychaetes collected in this study disperse along the substrate, while the copepods migrate into the water column and resettle to the substrate across broad areas (Walters \& Bell 1986, Bell \& Hicks 1991, Jørgensen \& Christie 2003, G. Rouse pers. comm.). Taxa known not to disperse in this pattern were excluded from the analyses (e.g. polychaetes in the families Maldanidae and Serpulidae). This difference in dispersal mode may cause copepod and polychaete assemblages to be affected differently by the size and isolation of neighbouring habitats over time (i.e. polychaetes take longer to disperse over the substrate and may be slower colonisers of isolated habitats), so sufficient numbers of habitats were constructed so that they could be independently sampled after 2 durations ( 2 and 13 d). Previous studies have shown that similar durations are sufficient for colonisation of macrofauna to natural levels (Virnstein \& Curran 1986, Bell \& Hicks 1991, Eggleston et al. 1999, Norderhaug et al. 2002). In contrast to adult dispersal, larvae and juveniles can settle in massive numbers, and growth of juveniles can be rapid. Therefore, larval and juvenile settlement has the potential to swamp any effects of the treatments on adult dispersal. To ensure that results were not overshadowed by juvenile recruitment, the experiment had to be run over a short period (13 d). Even over this short period, some juvenile polychaetes were found in habitats (in very low numbers), but they were omitted from the analyses.

Habitats that were not sampled (unsampled habitats), but were used as neighbours of the habitats targeted for sampling (sampled habitats), were placed on the experimental sand flat, in no particular arrangement, and left for 1 mo to allow macrofaunal assemblages to establish. After $1 \mathrm{mo}$, unsampled habitats were moved into position and sampled habitats were added to the sand flat according to the experimental design (i.e. pairs of habitats containing 1 unsampled habitat and 1 sampled habitat). After the appropriate duration (either 2 or $13 \mathrm{~d}$ ), each sampled habitat was removed from its boulder, placed in an individual plastic sample jar and preserved in $10 \%$ formalin in seawater for later identification of macrofauna. In the laboratory, samples were washed through a $100 \mu \mathrm{m}$ sieve along with the original water from the sample jar. Macrofauna retained by the sieve, along with fauna removed from habitats, were identified to morphospecies (henceforth called species), because this provided sufficient resolution to identify experimental effects. Other studies have used similar classification systems to identify treatment effects on species richness (Oliver \& Beattie 1996, Golden \& Crist 1999, Hall et al. 2000). Reference specimens were stored in $70 \%$ ethanol.

Statistical analyses. The interactive effects of size and isolation of neighbouring habitat on composition of copepod and polychaete assemblages were tested using 2-factor NP-MANOVA (non-parametric multivariate analysis of variance) (Anderson 2001) for experimental habitats sampled after 13 d. Data were presence/absence transformed to allow identification of patterns in composition of faunal assemblage (i.e. species richness). In this transformation, taxa are given a value of 1 if any individuals are present (regardless of number present) and a value of 0 if no individuals are present. Analyses were done using Bray-Curtis distances and p-values were obtained using 9999 permutations of the transformed data.

Treatment effects on species richness and animal abundance of copepods were tested using 3-factor ANOVAs (factors: time, size and isolation). Insufficient numbers of polychaetes were present after $2 \mathrm{~d}$ to complete a 3-factor analysis (only 2 individuals), so 2-factor ANOVAs (factors: size and isolation) were used for habitats sampled after $13 \mathrm{~d}$. Abundance data for copepods and polychaetes were transformed using Sqrt $(x+1)$ and Ln $(x+1)$, respectively, to remove heterogeneity in the data. Post-hoc Student Newman Keuls (SNK) comparison of means were used to identify ranking in factors when significant interaction terms were detected. Where SNK tests were used, no corrections (e.g. Bonferroni) were done to correct for 
Table 1. Number of morphospecies, individuals and main genera of the morphospecies in each family of polychaete that colonised the artificial habitats

\begin{tabular}{|c|c|c|c|}
\hline Family & $\begin{array}{c}\text { No. } \\
\text { morpho- } \\
\text { species }\end{array}$ & $\begin{array}{l}\text { No. } \\
\text { ind. }\end{array}$ & Main genera \\
\hline Eunicidae & 1 & 6 & Nematoneresis sp. \\
\hline Nereididae & 3 & 3 & Not identified to genus \\
\hline Opheliidae & 1 & 3 & Polyophthalmus sp. \\
\hline Polynoidae & 3 & 5 & Not identified to genus \\
\hline Sabellidae & 4 & 10 & $\begin{array}{l}\text { Amphicorinia sp. } \\
\text { Branchiomma sp. }\end{array}$ \\
\hline Syllidae & 8 & 39 & Exogone sp. \\
\hline Terebellidae & 2 & 8 & Not identified to genus \\
\hline
\end{tabular}

the increased error rate associated with multiple comparisons, but it is still expected that only 1 comparison in 20 would be significant by chance alone.

\section{RESULTS}

There were 75 individual polychaetes that colonised artificial habitats, which were classified into 22 morphospecies, from 7 families (Table 1). Of the 1479 individual copepods inhabiting the habitats, many are undescribed. All the copepods were from the orders Cyclopoida and Harpacticoida, and were included in the analysis as 10 morphospecies (6 cyclopoid and 4 harpacticoid).

The size and isolation of neighbouring habitats had different effects on the composition of copepod and polychaete assemblages. After $13 \mathrm{~d}$, the composition of copepod assemblages only differed between small habitats that were adjacent to small and large habitats when habitats were far apart (size $\times$ isolation interaction; $F_{1,24}=$ $3.88, \mathrm{p}=0.03$ ) (Fig. 2a, Table 2a,b). Polychaete assemblages were significantly effected by the isolation of habitats $\left(F_{1,24}=\right.$ $2.29, p=0.03$; Fig. 2b, Table 2a). This difference in composition is possibly due to the fact that one family of polychaetes, the Nereididae, was exclusively found in the near habitats, regardless of whether the neighbouring habitat was small or large.

The effects of size and isolation on species richness differed between copepods and polychaetes. When the neighbouring habitat was large, copepod richness was greater in near rather than far habitats (size $\times$ isolation interaction; $F_{1,48}=3.34$, $p=0.02$ ) (Fig. 3a, Table 3a,b), whereas polychaete species richness was always greater when neighbouring habitat was
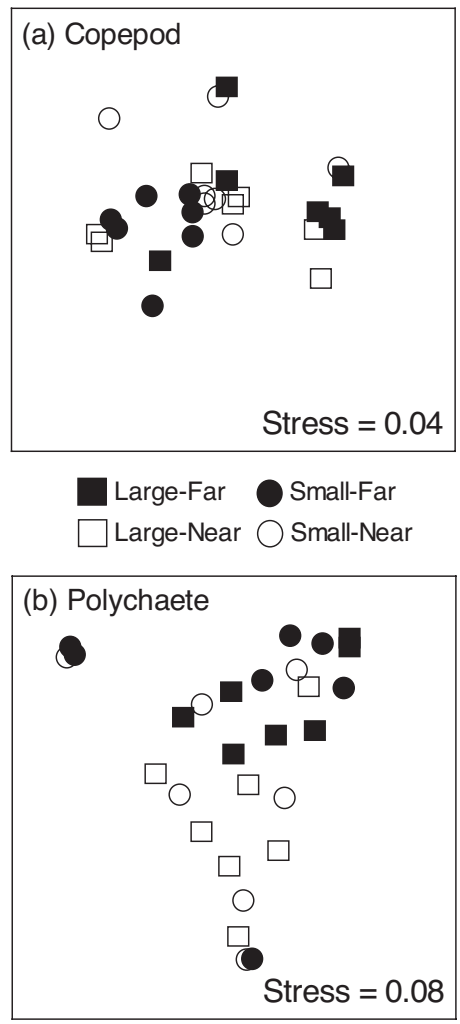

Fig. 2. nMDS plots of the composition of (a) copepods and (b) polychaetes from habitats near and far from small and large habitats

large $\left(F_{1,24}=9.32, \mathrm{p}=0.006\right)$ (Fig. 3b, Table 4$)$. The species richness of polychaetes (univariate statistics) was affected by size of habitat, whereas composition of the polychaete assemblage (see multivariate statistics in

Table 2. (a) Two-way NP-MANOVAs testing the relative effects of size of (small vs. large), and distance to (near vs. far) neighbouring habitat on composition of faunal assemblage of copepods and polychaetes after $13 \mathrm{~d}$, and (b) pairwise comparisons for the significant size $\times$ isolation term for copepod taxa. All data were presence/absence transformed. $p$ values in bold are significant

\begin{tabular}{|c|c|c|c|c|c|c|c|}
\hline \multicolumn{5}{|c|}{ (a) NP-MANOVA } & \\
\hline \multirow[t]{2}{*}{ Source } & \multirow[t]{2}{*}{ df } & \multicolumn{3}{|c|}{ Copepod } & & & \\
\hline & & MS & $F$ & $\mathrm{p}$ & MS & $\begin{aligned} \text { Polychaete } \\
\text { MS }\end{aligned}$ & $\mathrm{p}$ \\
\hline Size $(\mathrm{S})$ & 1 & 729.6 & 3.14 & 0.067 & 3958.8 & 1.06 & 0.394 \\
\hline Isolation (I) & 1 & 40.9 & 0.18 & 0.897 & 8565.1 & 2.29 & 0.035 \\
\hline $\mathrm{S} \times \mathrm{I}$ & 1 & 902.8 & 3.88 & 0.035 & 4160.2 & 1.11 & 0.366 \\
\hline Residual & 24 & 232.6 & & & 3744.5 & & \\
\hline \multicolumn{8}{|c|}{ (b) Pairwise comparisons of copepod composition } \\
\hline Factor & Level & & Int & raction & & $t$ & $\mathrm{p}$ \\
\hline \multirow[t]{2}{*}{ Size } & \multicolumn{2}{|l|}{ Small } & \multicolumn{2}{|c|}{ Near vs. Far } & & 1.53 & 0.18 \\
\hline & \multicolumn{2}{|l|}{ Large } & \multicolumn{2}{|c|}{ Near vs. Far } & & 1.15 & 0.33 \\
\hline \multirow[t]{2}{*}{ Isolation } & Near & & \multirow{2}{*}{\multicolumn{2}{|c|}{$\begin{array}{l}\text { Small vs. Large } \\
\text { Small vs. Larqe }\end{array}$}} & & 1.54 & 0.13 \\
\hline & Far & & & & & 2.11 & 0.03 \\
\hline
\end{tabular}


Table 3. (a) Three-factor ANOVAs testing the effects of time ( 2 vs. 13 d), size of (small vs. large), and distance to (near vs. far) neighbouring habitat on (i) the species richness and (ii) abundance of copepods, and (b) SNK tests on significant interaction terms for (i) richness and (ii) abundance. p values in bold are significant. Sqrt $(x+1)$ transformation was used on (ii) to meet assumptions of heterogeneity of data (Cochran's $C$-test)

\begin{tabular}{|c|c|c|c|c|c|c|c|c|c|c|}
\hline \multirow{3}{*}{$\begin{array}{l}\text { (a) ANOVA } \\
\text { Source }\end{array}$} & \multirow{3}{*}{$\mathrm{df}$} & \multirow{2}{*}{\multicolumn{3}{|c|}{ (i) Richness }} & \multirow{2}{*}{\multicolumn{3}{|c|}{ (ii) Abundance }} & \multirow[t]{3}{*}{ (b) SNK } & \multirow{3}{*}{ (i) Richness } & \multirow{3}{*}{$\begin{array}{l}\text { (ii) Abundance } \\
\text { after } 13 \mathrm{~d}\end{array}$} \\
\hline & & & & & & & & & & \\
\hline & & MS & $F$ & $\mathrm{p}$ & $\mathrm{MS}$ & $F$ & $\mathrm{p}$ & & & \\
\hline Time $(\mathrm{T})$ & 1 & 35.10 & 49.27 & $<0.0001$ & 106.64 & 66.40 & $<0.0001$ & Near & Small < Large & Small < Large \\
\hline Size (S) & 1 & $<0.01$ & 0.02 & 0.909 & 8.56 & 126.96 & 0.056 & Far & Small > Large & Small = Large \\
\hline Isolation (I) & 1 & $<0.01$ & 0.04 & 0.874 & 0.74 & 19.06 & 0.143 & Small & Near $<$ Far & Near $<$ Far \\
\hline $\mathrm{T} \times \mathrm{S}$ & 1 & 0.10 & 0.14 & 0.713 & 0.67 & 0.04 & 0.838 & Large & Near $>$ Far & Near $=$ Far \\
\hline $\mathrm{T} \times \mathrm{I}$ & 1 & 0.05 & 0.07 & 0.793 & 0.04 & 0.02 & 0.876 & & & \\
\hline $\mathrm{S} \times \mathrm{I}$ & 1 & 3.34 & 681.00 & 0.015 & 7.99 & 1.04 & 0.493 & & & \\
\hline $\mathrm{T} \times \mathrm{S} \times \mathrm{I}$ & 1 & $<0.01$ & $<0.01$ & 0.958 & 7.68 & 4.78 & 0.033 & & & \\
\hline Residual & 48 & 0.71 & & & 1.61 & & & & & \\
\hline
\end{tabular}

the previous paragraph) was affected by isolation of habitat. The difference in results between univariate and multivariate statistics is possibly an indication that some species were affected by isolation of habitats, but their numbers were not sufficient to cause a univariate difference. Again, the difference in composition of polychaete assemblage could have been due to the fact that Nereid polychaetes were only found in near habitats.

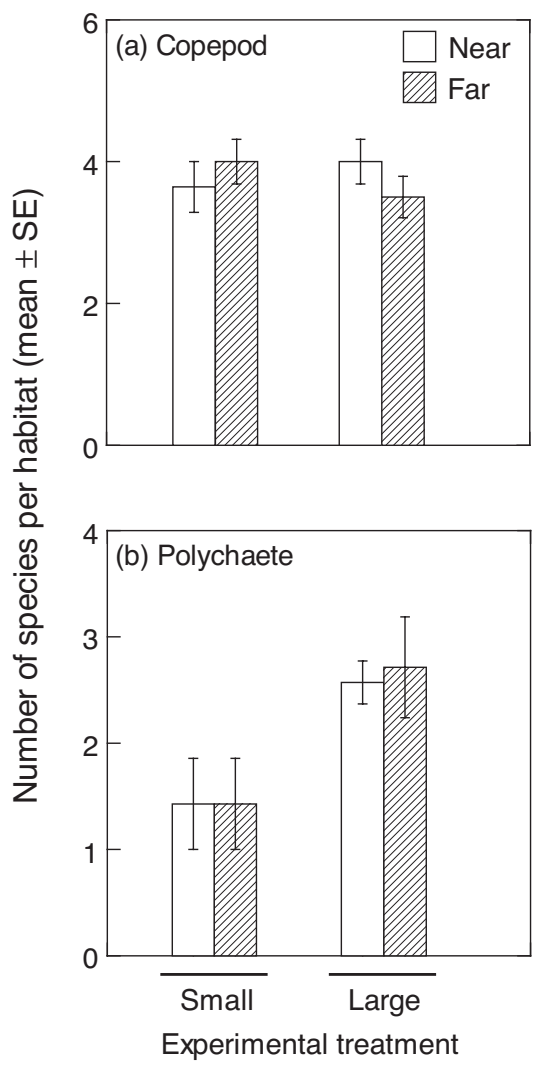

Fig. 3. Species richness (mean $\pm \mathrm{SE}$ ) of (a) copepods for combined 2 and $13 \mathrm{~d}$ samples and (b) polychaetes for $13 \mathrm{~d}$ samples
Size and isolation of habitats also affected abundance of copepods and polychaetes in different ways. Copepods colonised habitats at a faster rate than polychaetes. After $2 \mathrm{~d}$, mean copepod abundance was 11.75 (minimum 1, maximum 27) and polychaete 0.07 (minimum 0 , maximum 5). For copepod abundance, a significant 3way interaction was detected (time $\times$ size $\times$ isolation interaction; $\left.F_{1,48}=4.78, \mathrm{p}=0.03\right)$. SNK tests detected that there was no effect of size and isolation of habitats on copepod abundance after $2 \mathrm{~d}$, hence only $13 \mathrm{~d}$ data have been presented (Fig. 4a). After 13 d, abundance was greater when near to a large habitat (Fig. 4a, Table 3a,b). Furthermore, when the neighbouring habitat was small, abundance of copepods was greater when habitats were far apart (Fig. 4a, Table 3c). The abundance of polychaetes was affected by size of neighbouring habitat, so that abundance was greater when the neighbouring habitat was larger $\left(F_{1,24}=4.48, \mathrm{p}=0.04\right)$ (Fig. $4 \mathrm{~b}$, Table 4).

\section{DISCUSSION}

Populations in spatially segregated habitats are linked through dispersal and migration (Wiens et al. 1993, Han-

Table 4. Two-factor ANOVAs testing the effects of size of, and distance to, neighbouring habitats on (a) species richness and (b) abundance of polychaetes after $13 \mathrm{~d}$. Ln $(x+1)$ transformation was used on (b) to meet assumptions of heterogeneity of data (Cochran's $C$-test). $p$ values in bold are significant

\begin{tabular}{|lrrrcrrr|r|}
\hline \multirow{2}{*}{ Source } & df & \multicolumn{3}{c}{ (a) Richness } & \multicolumn{3}{c|}{ (b) Abundance } \\
& & MS & \multicolumn{1}{c|}{$F$} & p & MS & $F$ & p \\
\hline Size (S) & 1 & 10.32 & 9.32 & $\mathbf{0 . 0 0 5}$ & 0.97 & 4.48 & $\mathbf{0 . 0 4 4}$ \\
Isolation (I) & 1 & 0.04 & 0.03 & 0.859 & $<0.01$ & 0.02 & 0.890 \\
S $\times$ I & 1 & 0.04 & 0.03 & 0.859 & 0.08 & 0.37 & 0.549 \\
Residual & 24 & 1.10 & & & 0.21 & & \\
& & & & & & & \\
\hline
\end{tabular}




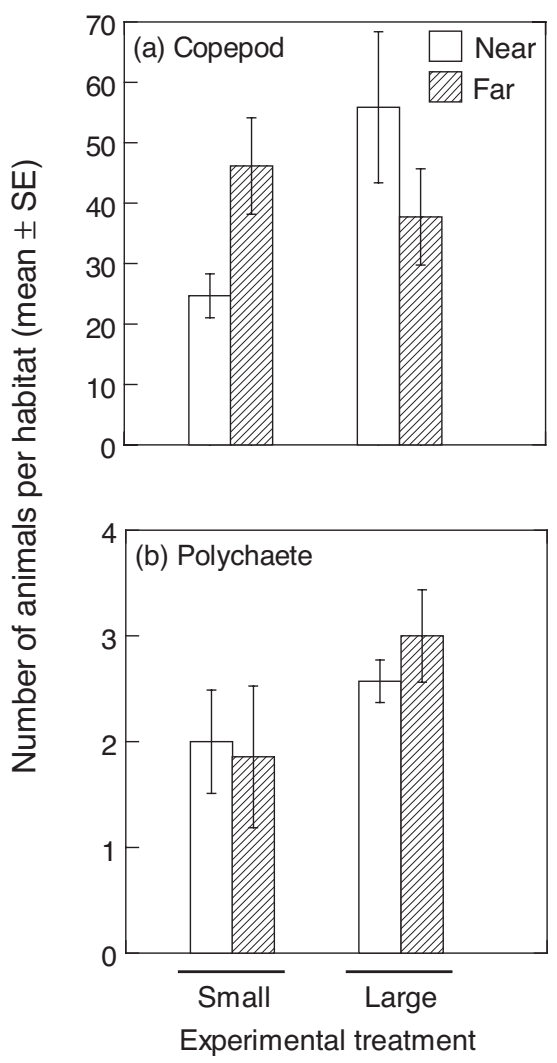

Fig. 4. Abundance (mean $\pm \mathrm{SE}$ ) of (a) copepods and (b) polychaetes in experimental habitats after $13 \mathrm{~d}$

ski 1999), but animals with different migration abilities will be differentially affected by habitat isolation (Bowman et al. 2002). Species that have greater adult migration abilities can disperse more easily between habitats (Smith \& Brumsickle 1989) and are less likely to be effected by habitat isolation. Our results support this idea, because the size of neighbouring habitat and distance to it had different effects on assemblage composition of polychaetes and copepods. The polychaetes, which are benthic crawlers and slower dispersers compared to copepods, were affected by isolation of habitats. In contrast, the copepods, which are water column swimmers and are able to cover greater distances over shorter time periods, were only affected by the size of neighbouring habitat when habitats were far apart. The differential effects of habitat isolation on polychaete and crustacean assemblages have also been reported in algal and seagrass habitats (Gunnill 1982a, Virnstein \& Curran 1986).

There is increasing evidence that animals with greater dispersal abilities are less affected by isolation of habitats. Howard (1985) demonstrated that crustaceans colonised habitats faster than gastropods and attributed this to their different dispersal modes. In fragmented forest landscapes, birds and mammals are affected differently by distance between habitats
(Andrén 1994, Delin \& Andrén 1999, Trzcinski et al. 1999), possibly because of their dispersal modes. It is possible that species with greater dispersal abilities (i.e. water column swimmers or aerial dispersers) are able to perceive habitats from greater distances (Bowman et al. 2002) and will be able to utilise habitats that are more isolated. Bowman et al. (2002) warned that the dispersal mode of a species needs to be taken into account when predicting the effects of size of habitat fragments. We suggest that dispersal modes also need to be considered when predicting the effects of habitat isolation (or habitat fragmentation per se), because increasing isolation is likely to disproportionately affect species with lower dispersal abilities.

In the current study, there were 2 possible sizes of habitat for each pair of experimental habitats, large and small. Within each area of habitat, increasing isolation did not cause a decrease in the amount of habitat, making this a true test of the effects of habitat isolation. For polychaetes, there was no effect of isolation of habitats on species richness and abundance. However, the nereid polychaetes found in this study were highly mobile (G. Rouse pers. comm.) but were only found in habitats near to neighbouring habitats. Isolation of habitats has been shown to limit migration in other polychaetes (Kelaher \& Rouse 2003) and gastropods (Virnstein \& Curran 1986). Therefore, it seems that for some species the distance between habitats is more important than the size of neighbouring habitats. Again, we caution that generalisations about the effects of habitat isolation should not be made without considering dispersal mode, because effects can be inconsistent within groups (e.g. forest birds; Trzcinski et al. 1999).

When habitats are near to each other, animals emigrating from habitats are more likely to perceive or encounter neighbouring habitats and are able to use these habitats for resources (Kareiva 1985). From this model, we predicted that species richness and abundance of animals would be greater in habitats that were close together. The logical derivation, therefore, is that when habitats are far apart, species diversity and animal abundance should be lower. However, we found that when the neighbouring habitat was small, copepod abundance was greater in habitats that were far apart, which was contrary to what was predicted. Virnstein \& Curran (1986), who found similar results for crustaceans, suggested that habitats far from neighbouring habitats would be colonised faster because animals will use any habitat when they are far from other refuges (i.e. the nearest refuge hypothesis). There is increasing evidence to support this pattern in marine systems, with more taxa and abundance of animals being found in isolated habitats in seagrass 
(Virnstein \& Curran 1986, Bell \& Hicks 1991) and brown algae (Gunnill 1982a,b).

The groups of animals that show greater diversity and abundance in isolated marine habitats seem to be highly mobile animals that disperse through the water column, such as crustaceans. The relatively larger volume of water surrounding isolated habitats (i.e. the water/habitat ratio) could mean that these habitats are colonised faster than habitats close together (Goodsell 2004) because animals settle in the nearest available habitat (Edgar 1992, Taylor \& Cole 1994). This model is supported by our observation of greater abundance of copepods in habitats far from small habitats. Furthermore, this pattern was not found for polychaetes (this study) or gastropods (Virnstein \& Curran 1986), which are benthic dispersers that do not migrate in the water column like copepods. However, if this pattern is to hold we should have also found greater numbers of animals and taxa in habitats far from large habitats. We suggest that this pattern is altered by the size of nearest habitat, where highly mobile fauna will tend to travel further to colonise larger habitats where they are accessible. However, when the nearest habitat is small, and further away, animals will colonise the closest available habitat.

Although it seems likely that the mode of adult movement caused the treatment effects seen, we were not able to directly test the rate of movement of the different taxa, and it is possible that some other factor contributed to the patterns. Biological differences that could contribute to the differences recorded include diet, predation and life history. As all sampled habitats were the same, regardless of treatment, it is unlikely that any difference in diet between taxa caused the patterns, because resources should not have varied between treatments. Similarly, reproductive mode is unlikely to have contributed to the patterns, because the experiment was designed to test hypotheses about adult mobility, so the experiments were carried out over a short time period. Furthermore, the few larvae that were found in samples were excluded from analyses. However, a difference in predation pressure between polychaetes and copepods could have contributed to the patterns. If copepods were to experience lower predation pressure than polychaetes, then you may expect to see a different effect of habitat isolation on polychaetes and copepods, regardless of mode of adult movement. Further, if polychaetes move at a slower speed between habitats than copepods, the chance of encountering a predator would increase with isolation of habitat.

Habitat loss has consistently negative effects on diversity and abundance of animals in aquatic and terrestrial systems (Andrén 1994, Goodsell \& Connell
2002, Fahrig 2003). Andrén (1994) suggests that small habitats near large habitats will not suffer severe species losses as a result of habitat isolation. However, if the large habitat is reduced in size a corresponding loss in species could be expected. Our results support this model. By reducing the amount of habitat available in the habitat pairs, we observed a corresponding reduction in diversity. This effect was consistent, regardless of dispersal mode, suggesting that loss of habitat area has detrimental effects on species, independent of dispersal ability. This result suggests that conservation goals in landscapes could be achieved, even with small protected habitats, if the neighbouring habitat is large. Importantly, if the large, unprotected habitat is subsequently reduced, the conservation value of neighbouring habitats will also be reduced, but this requires further research on larger scales.

In conclusion, a reduction in the size of neighbouring habitats, and therefore the amount of habitat in landscapes, has consistent negative effects on diversity and abundance of animals (Fahrig 2003). However, isolation of habitats has differential effects on animals depending on their dispersal mode. Both these factors may be important considerations when planning conservation areas. If a certain sized habitat is available for protection, then benefits could be increased by placing such areas close to larger habitats of a similar type. This placement could reduce the negative effects of habitat isolation and fragmentation. These considerations have broader implications, however, as they suggest that attempts should still be made to reduce impacts on large habitats outside protected areas; otherwise conservation efforts inside these areas may be compromised.

Acknowledgements. We thank Dr Greg Rouse (South Australian Museum) and Dr Genefor Walker-Smith (Tasmanian Museum) for their assistance with identification of polychaetes and copepods (respectively) and critical information on their movement. The field component of this study would not have been possible without the assistance of Andrew Irving. Thanks to Lisa Farroway and Thomas Grieg for assistance in making experimental habitats. This research was supported by a Wildlife Conservation Fund (South Australia) research grant and an APA to B.D.R, an ARC QEII Fellowship to B.M.G and an ARC Discovery grant to S.D.C and B.M.G.

\section{LITERATURE CITED}

Anderson MJ (1998) Effects of patch size on colonisation in estuaries: revisiting the species-area curve. Oecologia 118:87-98

Anderson MJ (2001) A new method for non-parametric multivariate analysis of variance. Austral Ecol 26:32-46

Andrén H (1994) Effects of habitat fragmentation on birds and mammals in landscapes with different proportions of suitable habitat: a review. Oikos 71:355-366 
Bell SS, Hicks GRF (1991) Marine landscapes and faunal recruitment: a field test with seagrasses and copepods. Mar Ecol Prog Ser 73:61-68

Bowman J, Cappuccino N, Fahrig L (2002) Patch size and population density: the effect of immigration behaviour. Conserv Ecol 6:9-16

Collinge SK (1998) Spatial arrangement of habitat patches and corridors: clues from ecological field experiments. Landscape Urban Plann 42:157-168

Costello MJ, Myers AA (1996) Turnover of transient species as a contributor to the richness of a stable amphipod (Crustacea) fauna in a sea inlet. J Exp Mar Biol Ecol 202:49-62

Delin AE, Andrén H (1999) Effects of habitat fragmentation on Eurasian red squirrel (Sciurus vulgaris) in a forest landscape. Landscape Ecol 14:67-72

Edgar GJ (1992) Patterns of colonization of mobile epifauna in a Western Australian seagrass bed. J Exp Mar Biol Ecol 157:225-246

Eggleston DB, Etherington LL, Elis WE (1998) Organism response to habitat patchiness: species and habitatdependent recruitment of decapod crustaceans. J Exp Mar Biol Ecol 223:111-132

Eggleston DB, Elis WE, Etherington LL, Dahlgren CP, Posey MH (1999) Organism responses to habitat fragmentation and diversity: habitat colonization by estuarine macrofauna. J Exp Mar Biol Ecol 236:107-132

Fahrig L (2003) Effects of habitat fragmentation on biodiversity. Ann Rev Ecol Evol Syst 34:487-515

Flather $\mathrm{CH}$, Bevers $\mathrm{M}$ (2002) Patchy reaction-diffusion and population abundance: the relative importance of habitat amount and arrangement. Am Nat 159:40-56

Fleishman E, Ray C, Sjogren-Gulve P, Boggs CL, Murphy DD (2002) Assessing the roles of patch quality, area and isolation in predicting metapopulation dynamics. Conserv Biol 16:706-716

Golden DM, Crist TO (1999) Experimental effects of habitat fragmentation on old-field canopy insects: community, guild and species responses. Oecologia 118:371-380

Goodsell PJ (2004) Consequences of disturbance of subtidal floral and faunal diversity. $\mathrm{PhD}$ thesis, University of Adelaide

Goodsell PJ, Connell SD (2002) Can habitat loss be treated independently of habitat configuration? Implications for rare and common taxa in fragmented landscapes. Mar Ecol Prog Ser 239:37-44

Gunnill FC (1982a) Effects of plant size and distribution on the numbers of invertebrate species and individuals inhabiting the brown alga Pelvetia fastigiata. Mar Biol 69: 263-280

Gunnill FC (1982b) Macroalgae as habitat patch islands for Scutellidium lamellipes (Copepoda: Harpacticoida) and Ampithoe tea (Amphipoda: Gammaridae). Mar Biol 69: 103-116

Hall SJ, Gray SA, Hammett ZL (2000) Biodiversity-production relations: an experimental evaluation of mechanisms. Oecologia 122:545-555

Hanski I (1999) Habitat connectivity, habitat continuity, and metapopulations in dynamic landscapes. Oikos 87: 209-219

Holmquist JG (1998) Permeability of patch boundaries to benthic invertebrates: influences of boundary contrast, light level, and faunal density and mobility. Oikos 81: 558-566

Howard RK (1985) Measurements of short-term turnover of epifauna within seagrass beds using an in situ staining method. Mar Ecol Prog Ser 22:163-168

Howard RK, Edgar GJ, Hutchings PA (1989) Faunal assemblages of seagrass beds. In: Larkum AWD, McComb AJ,
Shepherd SA (eds) Biology of seagrasses: a treatise on the biology of seagrasses with special reference to the Australian region. Elsevier, Amsterdam, p 536-564

Jørgensen NM, Christie H (2003) Diurnal, horizontal and vertical dispersal of kelp-associated fauna. Hydrobiologia 503:69-76

Kareiva P (1985) Finding and losing host plants by Phyllotreta: patch size and surrounding habitat. Ecology 66: 1809-1816

Kelaher BP, Rouse GW (2003) The role of colonization in determining spatial patterns of Proscoloplos bondi sp. nov. (Orbiniidae: Annelida) in coralline algal turf. Mar Biol 143: 909-917

Lee M, Fahrig L, Freemark K, Currie DJ (2002) Importance of patch scale vs landscape scale on selected forest birds. Oikos 96:110-118

Lenihan HS, Peterson CH, Byers JE, Grabowski JH, Thayer GW, Colby DR (2001) Cascading of habitat degradation: oyster reefs invaded by refugee fishes escaping stress. Ecol Appl 11:764-782

Lomolino MV, Perault DR (2001) Island biogeography and landscape ecology of mammals inhabiting fragmented, temperate rain forests. Global Ecol Biogeo 10:113-132

Melville A, Connell SD (2001) Experimental effects of kelp canopies on subtidal coralline algae. Austral Ecol 26: 102-108

Myers AA, Southgate T (1980) Artificial substrates as a means of monitoring rocky shore cryptofauna. J Mar Biol Assoc UK 60:963-975

Norderhaug KM, Christie H, Rinde E (2002) Colonisation of kelp imitations by epiphyte and holdfast fauna; a study of mobility patterns. Mar Biol 141:965-973

Oliver I, Beattie AJ (1996) Invertebrate morphospecies as surrogates for species: a case study. Conserv Biol 10:99-109

Pickett STA, White PS (1985) The ecology of natural disturbance and patch dynamics. Academic Press, San Diego, CA

Smith CM, Brumsickle SJ (1989) The effects of patch size and substrate isolation on colonization modes and rates in an intertidal sediment. Limnol Oceanogr 34:1263-1277

Smith SDA, Rule MJ (2002) Artificial substrata in a shallow sublittoral habitat: do they adequately represent natural habitats or the local species pool? J Exp Mar Biol Ecol 277: 25-41

Tanner JE (2003) Patch shape and orientation influences on seagrass epifauna are mediated by dispersal abilities. Oikos 100:517-524

Taylor RB, Cole RG (1994) Mobile epifauna on subtidal brown seaweeds in northeastern New Zealand. Mar Ecol Prog Ser 115:271-282

Trzcinski MK, Fahrig L, Merriam G (1999) Independent effects of forest cover and fragmentation on the distribution of forest breeding birds. Ecol Appl 9:586-593

Virnstein RW, Curran MC (1986) Colonization of artificial seagrass versus time and distance from source. Mar Ecol Prog Ser 29:279-288

Waage-Nielsen E, Christie H, Rinde E (2003) Short-term dispersal of kelp fauna to cleared (kelp-harvested) areas. Hydrobiologia 503:77-91

Walters K, Bell SS (1986) Diel patterns of active vertical migration in seagrass meiofauna. Mar Ecol Prog Ser 34: 95-103

Wellenreuther M, Connell SD (2002) Response of predators to prey abundance: separating the effects of prey density and patch size. J Exp Mar Biol Ecol 273:61-71

Wiens JA, Stenseth NC, Van Horne B, Ims RA (1993) Ecological mechanisms and landscape ecology. Oikos 66: $369-380$ 